\title{
Group 3 innate lymphoid cells regulate neutrophil migration and function in human decidua
}

\author{
D Croxatto ${ }^{1}$, A Micheletti $^{2}$, E Montaldo ${ }^{3}$, P Orecchia ${ }^{1}$, F Loiacono ${ }^{3}$, F Canegallo ${ }^{3}$, F Calzetti ${ }^{2}$, \\ E Fulcheri $^{3,4}$, E Munari ${ }^{5,6}$, A Zamò ${ }^{5}$, PL Venturini ${ }^{7,8}$, L Moretta $^{9}$, MA Cassatella $^{2}$, MC Mingari ${ }^{1,7,10}$ and $^{3}$ \\ P Vacca ${ }^{1,10}$
}

Innate lymphoid cells (ILCs) have a central role in innate defenses against pathogens, lymphoid organogenesis, and tissue remodeling. They have been detected in human decidua, however, their role in this tissue remains unclear. Successful pregnancy requires an early inflammatory phase favoring implantation and tissue remodeling as well as a subsequent regulatory phase to prevent fetal rejection and supporting neoangiogenesis. Here, we show that, during the first trimester of pregnancy, neutrophils infiltrate decidua basalis and are more abundant in normal pregnancy than in spontaneous miscarriages. Decidual neutrophils localize in proximity of $\mathrm{NCR}^{+}$ILC3, which may influence neutrophil migration and survival given their production of CXCL8 and granulocyte macrophage colony-stimulating factor (GM-CSF). Moreover, NCR ${ }^{+}$ILC3-derived GM-CSF was found to induce the expression of heparin-binding EGF-like growth factor and IL1ra in neutrophils, two proteins/cytokines involved in tissue remodeling and maintenance of pregnancy. Our data suggest that the simultaneous presence of $\mathrm{NCR}^{+} \mathrm{ILC} 3$ and neutrophils in decidual tissues and their possible cross talk, may have a role in the early phases of pregnancy.

\section{INTRODUCTION}

Innate lymphoid cells (ILCs) are developmentally related cells that have an important role in innate defenses against different pathogens, in generation of secondary lymphoid organs, and in tissue remodeling. Three main groups of ILCs have been identified according to phenotypic and functional characteristics. ${ }^{1,2}$ Natural killer (NK) cells are well-known cytolytic effector cells that have been assigned to ILC1 group. They exert a defensive role primarily against viral infections and tumor growth. ${ }^{3}$ Interestingly, NK cells with particular phenotypic and functional characteristics are present in human and murine decidua during the early phase of pregnancy. ${ }^{4-7}$ In human decidua, they represent $50-70 \%$ of decidual lymphoid cells, are poorly cytolytic, and produce low amounts of IFN $\gamma$ and TNF, typical NK-derived cytokines. ${ }^{4,5,8}$ Instead, they release cytokines/chemokines involved in neoangiogenesis, tissue remodeling, and placentation. ${ }^{8,9}$ Decidual NK cells (dNK) have been shown to interact with resident $\mathrm{CD} 14^{+}$myeloid cells and to participate in the induction of regulatory $\mathrm{T}$ cells that are essential for fetomaternal tolerance. ${ }^{10}$ More recently, we identified two additional ILC populations in human decidua, namely Natural Cytotoxic Receptors ${ }^{+}$ILC3 $\left(\mathrm{NCR}^{+}\right.$ILC3) and Lymphoid Tissue inducer-like (LTi-like) cells. ${ }^{11}$ ILC3 have been shown to predominate and exert their function primarily in mucosal tissues. ${ }^{1,12}$ We showed that decidual (d) ILC3 mainly produce CXCL8 $8{ }^{11}$ a chemokine that has an important role in decidual tissue building/remodeling. ${ }^{8}$ However, other factors mediating this function and thus contributing to a successful pregnancy have been identified such as heparinbinding EGF-like growth factor (HB-EGF) ${ }^{13,14}$ HB-EGF is a fibrogenic cytokine that has been reported to regulate the interactions between endometrium and implanting blastocyst

\footnotetext{
${ }^{1}$ Department of Experimental Medicine (DIMES), University of Genoa, Genoa, Italy. ${ }^{2}$ Department of Medicine, Section of General Pathology, School of Medicine, University of Verona, Verona, Italy. ${ }^{3} \mathrm{G}$. Gaslini Institute, Genoa, Italy. ${ }^{4}$ Department of Scienze Chirurgiche e Diagnostiche integrate (DISC), University of Genoa, Genoa, Italy. ${ }^{5}$ Department of Public Health and Community Medicine, Section of Pathological Anatomy, School of Medicine, University of Verona, Verona, Italy. ${ }^{6}$ Department of Pathology Sacro Cuore Hospital, Verona, Italy. ${ }^{7}$ IRCCS AOU San Martino-IST, Genoa, Italy. ${ }^{8}$ Department of Neuroscienze, Riabilitazione, Oftalmologia, Genetica e Scienze Materno-infantili, University of Genoa, Genoa, Italy and ${ }^{9}$ Ospedale Pediatrico Bambino Gesù, Viale Ferdinando Baldelli, Roma, Italy. Correspondence: L Moretta (lorenzo.moretta@opbg.net) ${ }^{10}$ Equivalent co-senior authors. 
and to promote angiogenesis at the fetomaternal interface. ${ }^{13,14}$ However, the decidual cell type(s) responsible for HB-EGF production has not been identified yet. Notably, this factor is produced by peripheral neutrophils (pNs) upon granulocyte macrophage colony-stimulating factor (GM-CSF) stimulation. ${ }^{15} \mathrm{~A}$ recent study revealed the presence of neutrophils with pro-angiogenic capability in human decidua during the second trimester of pregnancy. ${ }^{16}$ However, the identification of decidual neutrophils ( $\mathrm{dNs}$ ) during the first trimester of pregnancy is still lacking.

Neutrophils are major players during acute inflammation. They are phagocytic cells that release granules containing lytic enzymes and produce reactive oxygen intermediates with antimicrobial activity. ${ }^{17}$ Under physiological conditions, neutrophils are present in peripheral blood and in different tissues such as bone marrow and spleen. ${ }^{18,19}$ Notably, neutrophil numbers rapidly increase in damaged tissues, as they are usually the first cells to be recruited at inflammatory sites, where they can capture and kill microbes. ${ }^{17}$ Although neutrophils are typically short-lived (few hours) cells, they may survive much longer at inflammatory sites upon exposure to cytokines such as GM-CSF, IFN $\gamma$, and TNF. ${ }^{20}$ Interestingly, in addition to their pro-inflammatory function, they may also regulate angiogenesis, tissue remodeling, and immune responses. ${ }^{21-23}$ Accordingly, neutrophils release, either spontaneously or after stimulation, various cytokines/chemokines involved in host defenses and angiogenesis, as well as factors with antiinflammatory activity determining the resolution of inflammatory responses. ${ }^{22}$ In this context, it has been shown that neutrophils with anti-inflammatory/suppressive function may be present in the tumor microenvironment and chronic/ inflammatory diseases. ${ }^{18}$ Furthermore, it has been suggested that neutrophils represent cells linking the two arms of the immune system, as they may engage bidirectional interactions with various cell types of both innate and adaptive immunity. ${ }^{18}$ In particular, in inflamed tissues, neutrophils can interact with macrophages, dendritic cells, B and T lymphocytes, and NK cells. $^{18,20,24-30}$

In this study, we show that neutrophils are present in human decidua during the first trimester of normal pregnancy. By contrast, a lower frequency of neutrophils was detected in pathological decidual samples. dNs, once isolated, were found to display an activated phenotype and a higher resistance to apoptosis. We also demonstrate that the numbers of $\mathrm{NCR}^{+}$ ILC3 infiltrating decidual tissues positively correlate with those of infiltrating neutrophils. Accordingly, we show that CXCL8 and GM-CSF released by $\mathrm{NCR}^{+}$ILC3 in vitro can induce neutrophil migration and survival, respectively. Moreover, $\mathrm{dN}$ locally expressed HB-EGF, a factor that promotes neoangiogenesis and sustains blastocyst implantation. ${ }^{13,14}$ Finally, we show that $\mathrm{NCR}^{+}$ILC3-derived GM-CSF induces in $\mathrm{pNs}$ the expression of HB-EGF and of IL1ra that, besides its antiinflammatory activity, is known to mediate trophoblast invasion. $^{31,32}$ Overall, our study suggests that ILC3 and neutrophils may be involved in the induction and maintenance of pregnancy.

\section{RESULTS}

Neutrophils are present in decidua during the first trimester of pregnancy

In order to investigate whether neutrophils are present in human decidua during the first trimester of pregnancy, we first performed immunohistochemical analysis of decidual tissues derived from either "normal" pregnancy (i.e., samples from pregnancy termination requested for social reasons that did not display any evident pathological causes) or spontaneous miscarriages caused by different pathologies. As illustrated in Figure 1a, immunostaining of normal pregnancy samples, using the granulocyte marker CD15, showed the presence of $\mathrm{CD}^{+} 5^{+}$cells in decidua basalis (DB), i.e., an area mainly involved in tissue remodeling and in physiological decidual implant reaction, but not in decidua parietalis (DP). We also investigated whether $\mathrm{CD} 15^{+}$cells were present in decidual sections derived from spontaneous miscarriages (8-12 weeks) caused by different pathologies. ${ }^{33}$ We detected a significant lower frequency of $\mathrm{CD}_{1}{ }^{+}$cells in the $\mathrm{DB}$ of pathological samples than in normal pregnancy (Figure 1a-f). At a higher magnification, $\mathrm{CD}_{15}{ }^{+}$cells displayed a typical neutrophil morphology (Figure 1g). Next, dNs were analyzed by flow cytometry in comparison with peripheral blood neutrophils (pNs) present in non-pregnant healthy donors. Neutrophils were identified on the basis of their high forward scatter and side scatter, as well as of $\mathrm{CD} 45^{+} \mathrm{CD} 16^{+} \mathrm{CD} 14^{\mathrm{dim}} \mathrm{CD} 15^{+}$ $\mathrm{CD} 6 \mathrm{~b}^{+}$phenotype (Figure $\mathbf{1 h}$ and Supplementary Figure S1a online). Freshly isolated dNs displayed significantly higher expression of the surface markers CD15 and CD11b than pNs (Figure 1h-i). On the contrary, pNs expressed higher levels of CD62L (Figure 1h-i). To exclude the possibility that these differences were simply related to the pregnancy status, the same comparative analysis was performed on $\mathrm{pNs}$ isolated from pregnant and non-pregnant donors. No significant differences in surface marker expression were detected (Figure 1i), which suggests that pregnancy itself does not influence the phenotype of pNs. Notably, after $24 \mathrm{~h}$ of culture, $\mathrm{dNs}$ were mostly annexin $\mathrm{V}$-negative, which indicates a significantly higher resistance to apoptosis than pNs, at least in vitro (Figure 1j). Interestingly, leukocytes isolated from decidua also contained, in the purified mononuclear cell fraction, a population of low-density neutrophils (LD-dNs), characterized by the $\mathrm{CD} 45^{+} \mathrm{CD} 16^{+} \mathrm{CD} 14{ }^{\mathrm{dim}} \mathrm{CD} 15^{+} \mathrm{CD} 66 \mathrm{~b}^{+}$ phenotype (Supplementary Figure S1a). Previous studies showed that LD-dNs were present in tumor microenvironment and in chronic/inflammatory diseases where they usually display immunosuppressive properties. ${ }^{18}$ In order to assess whether these cells could exert immunosuppressive activity also in decidual tissues, we performed co-culture experiments using either LD-dNs or normal density dNs (ND-dNs) with allogenic T cells. As shown in Supplementary Figure S1b, $\mathrm{T}$-cell proliferation was not affected by the presence of either LD-dNs or ND-dNs, thus suggesting that neither LD-dNs nor ND-dNs exert an immunosuppressive activity. Taken together, these data suggest that, during the first trimester of pregnancy, neutrophils are present in human 

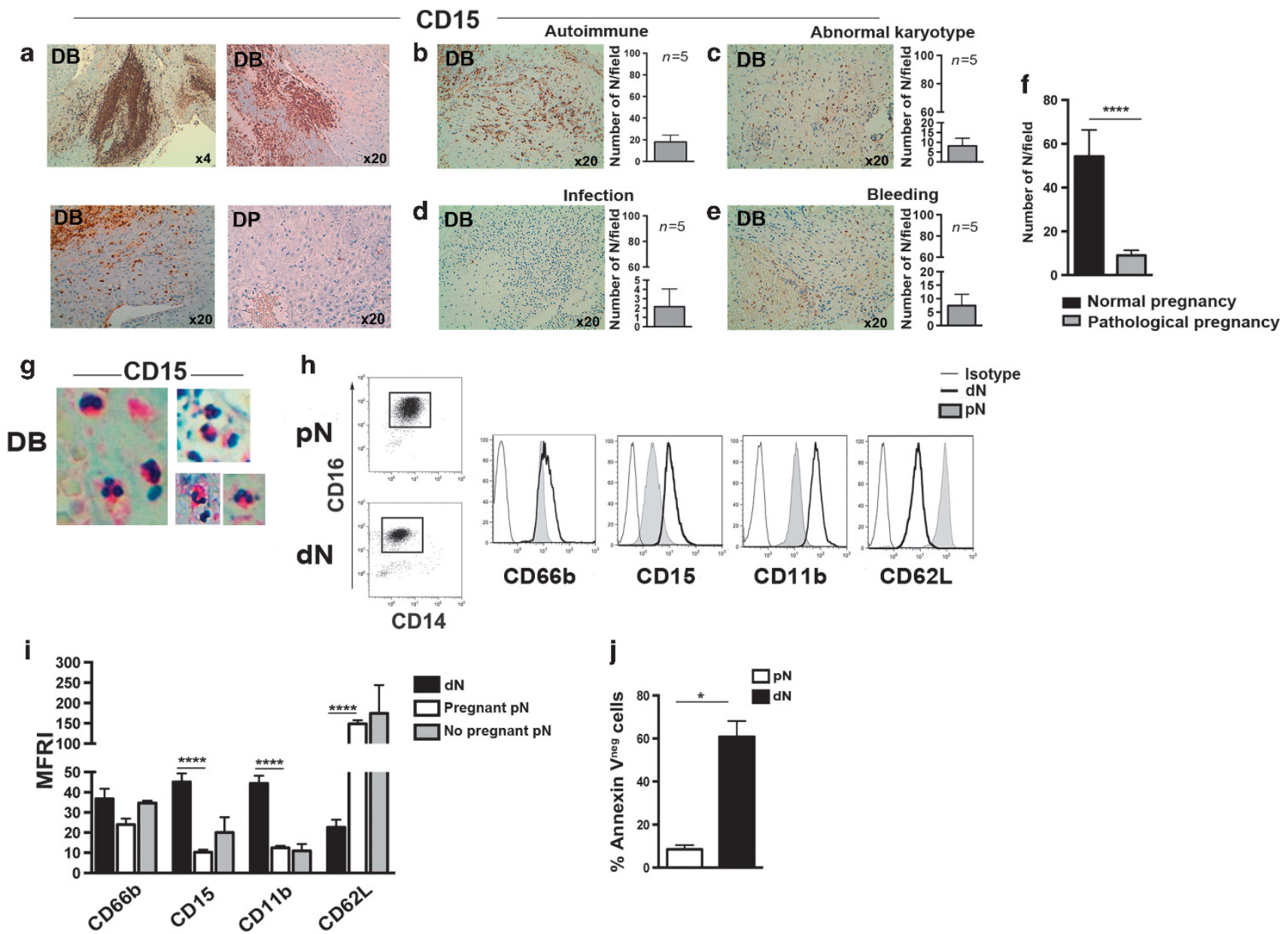

Figure 1 Identification of neutrophils in human decidua during the first trimester of pregnancy. (a-e) Immunohistochemical analysis of CD15 ${ }^{+}$ neutrophils (brown). The magnification is indicated. (a) Normal pregnancy. Three representative staining out of five performed. (b-e) Pathological pregnancy; immunohistochemistry of one representative donor out of five different patients for each miscarriage cause. Mean numbers/field ( \pm s.e.m.) of $\mathrm{CD}^{+} 5^{+}$cells. The number of patients is indicated on the graph. (b) Autoimmune miscarriage, (c) abnormal karyotype miscarriage, (d) infection, and (e) embryo detach following massive uterine bleeding. (f) Numbers of neutrophils/field in samples from normal $(n=10)$ and pathological $(n=20)$ pregnancy. The mean number/field ( \pm s.e.m.) of $\mathrm{CD}_{1}{ }^{+}$cells enumerated, by three independent observers, in five independent fields for each patient. Statistical analysis was performed using Mann-Whitney test. (g) Magnification of CD15 ${ }^{+}$neutrophils in DB of different decidua samples. (h) Flow cytometric analysis of neutrophils isolated from decidua (d) (black lines) and peripheral blood (p) of non-pregnant women (filled gray profiles). In left panels, cells characterized by high SSC and FSC were gated as CD45 ${ }^{+} \mathrm{CD} 16^{+} \mathrm{CD} 14^{\mathrm{dim}}$ and analyzed for the indicated markers (in right panels). One representative experiment out of 15 performed. (i) Comparative analysis of the MFRI \pm s.e.m. MFRI of different markers expressed by dN (black bars; $n=14-17$ donors), $\mathrm{pN}$ from pregnant women (white bars; $n=12-15$ donors), or not pregnant (grey bars; $n=3$ donors). MFRI was calculated by dividing the MFI of each marker with MFI of the respective nonspecific isotype control. Statistical analysis was performed using Mann-Whitney test. (j) Percentages of annexin V-negative neutrophils \pm s.e.m. isolated from decidua (black bar; $n=3$ donors) and peripheral blood (white bar; $n=5$ donors) cultured for $24 \mathrm{~h}$ in medium $+10 \%$ of serum. Statistical analysis was performed using Mann-Whitney test. FSC, forward scatter; MFRI, mean fluorescence ratio intensity; SSC, side scatter.

decidua, where they display an activated phenotype and, likely, an enhanced resistance to apoptosis.

Decidual $\mathrm{CD}^{-}{ }^{-} \mathrm{CD} 56^{+}$cells promote neutrophil migration, survival, and activation via the release of soluble factors Previous data indicated that NK cells are the most abundant lymphoid population in human decidua during the first trimester of pregnancy. ${ }^{5,8,34}$ As dNK cells have been shown to interact with other cell types present in the decidual microenvironment, including myeloid and trophoblast cells, ${ }^{9,10}$ we investigated whether $\mathrm{dNK}$ cells (identified as $\mathrm{CD} 3^{-} \mathrm{CD} 56^{+}$ cells) could influence some phenotypic and/or functional characteristics of neutrophils in vitro. We first evaluated whether $\mathrm{dCD} 3^{-} \mathrm{CD} 56^{+}$cells were capable of recruiting $\mathrm{pNs}$ via the release of CXCL8, one of the most potent chemokines inducing neutrophil migration. ${ }^{35}$ Unlike $\mathrm{pCD} 3^{-} \mathrm{CD} 56^{+}$cells, dCD3 ${ }^{-}{ }^{-} \mathrm{CD} 56^{+}$cells spontaneously released high amounts of CXCL8 (Figure 2a). In addition, pNs expressed higher levels of CXCL8 receptors (CXCR1 and CXCR2) than dNs (Figure 2b). Notably, the CXCL8 released by $\mathrm{dCD} 3{ }^{-} \mathrm{CD} 56^{+}$cells resulted biologically active in promoting pNs migration (Figure 2c). In the presence of either a neutralizing anti-CXCL8 ( $\alpha$-CXCL8) monoclonal antibody $(\mathrm{mAb})$ or of a CXCR1 and CXCR2 inhibitor, neutrophil migration was significantly decreased 
a

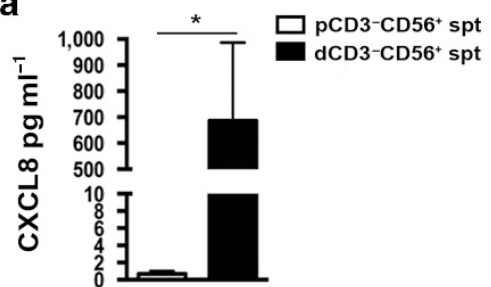

b

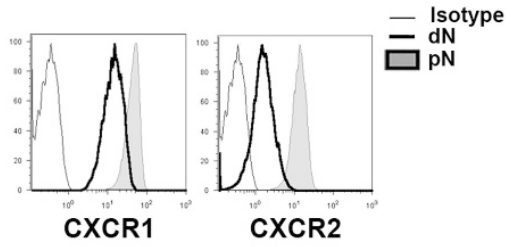

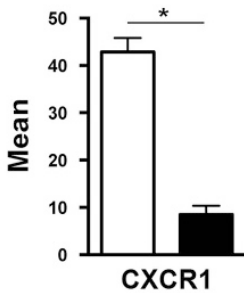

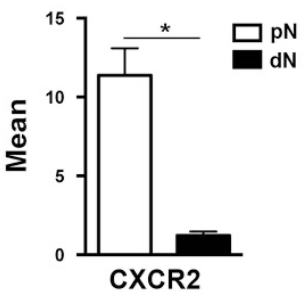

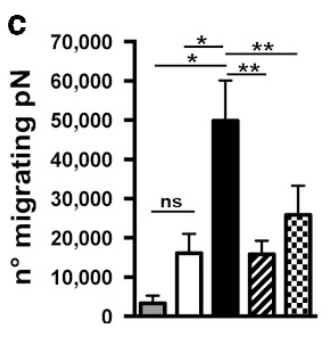

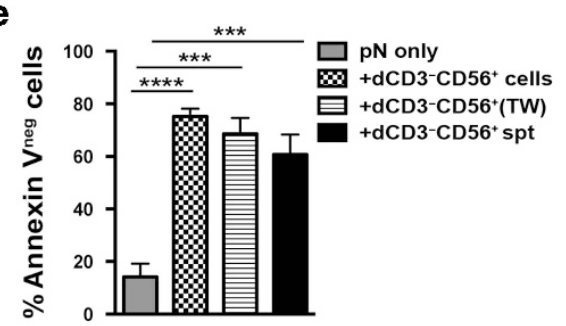

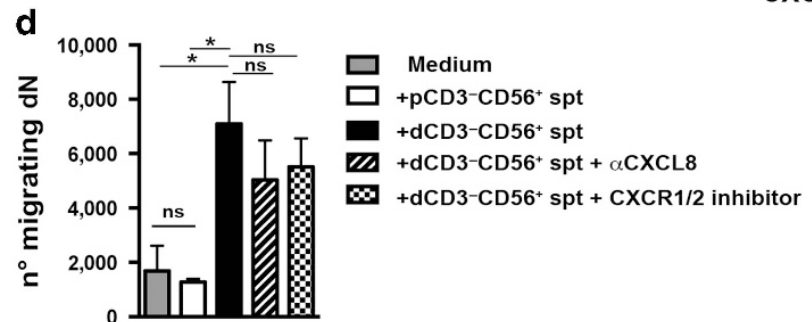

f

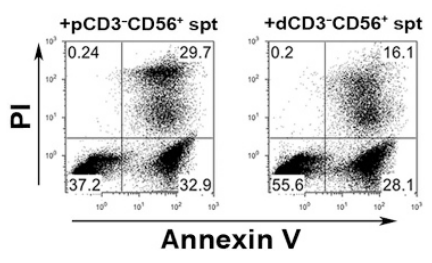

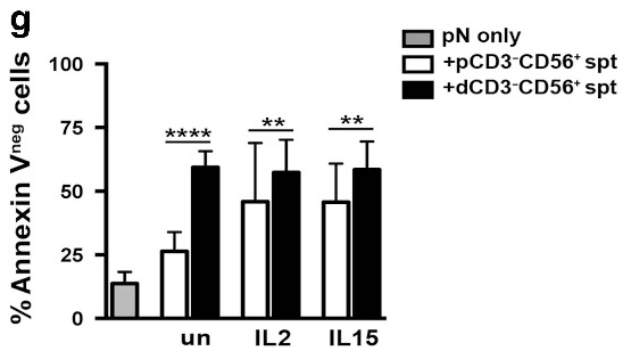

Figure 2 Decidual $\mathrm{CD}^{-}{ }^{-} \mathrm{CD} 56^{+}$cells promote neutrophil migration and survival. (a) Concentration (pg ml ${ }^{-1}$ ) of CXCL8 (mean \pm s.e.m.) in spt derived from d- or pCD3 ${ }^{-} \mathrm{CD}_{5} 6^{+}$cells cultured for $48 \mathrm{~h}$ in medium, in the absence of stimuli $(n=3-5)$. Statistical analysis was performed using Mann-Whitney test. (b) Flow cytometric analysis for the indicated markers of neutrophils isolated from decidua (d) (black lines; $n=6$ ) and peripheral blood ( $p$ ) of pregnant women (filled grey profiles; $n=5$ ). One representative experiment and mean fluorescence intensity (mean) \pm s.e.m. Statistical analysis was performed using Mann-Whitney test. (c, d) Number of migrating cells \pm s.e.m. (c) pN were plated in the TW (upper chamber) and incubated with pCD3 ${ }^{-}$CD56 $^{+}$ $(n=7)$ or dCD3 ${ }^{-} \mathrm{CD}_{56}{ }^{+} \mathrm{spt}(n=7)$ (lower chamber), and the number of migrating $\mathrm{pN}$ through the TW was measured. Experiments were performed either in the absence or in the presence of neutralizing $\alpha$-CXCL8 mAb $(n=7)$ or of CXCR1/CXCR2 inhibitor $(n=7)$. Statistical analysis was performed using Wilcoxcon matched paired test. (d) dNs were plated in the TW (upper chamber) and incubated with pCD3 ${ }^{-} \mathrm{CD}^{-} 6^{+}(n=4)$ or dCD3 ${ }^{-}$CD56 ${ }^{+}$spt $(n=6)$ (lower chamber), and the number of migrating dNs through the TW was measured. Experiments were performed either in the absence or in the presence of neutralizing $\alpha$-CXCL8 mAb $(n=3)$ or CXCR1/CXCR2 inhibitor $(n=7)$. Statistical analysis was performed using Mann-Whitney test. (e-g) Percentages of annexin V-negative neutrophils \pm s.e.m. Statistical analysis was performed using Mann-Whitney test. (e) pNs were cultured for $48 \mathrm{~h}$ alone $(n=7)$; with unstimulated dCD3 ${ }^{-} \mathrm{CD}_{5} 6^{+}$cells in direct contact (1:5 ratio; $\left.n=13\right)$ or separated by TW $(n=4)$; or with unstimulated dCD3 ${ }^{-}$CD56 ${ }^{+}$spt $(n=9)$ and analyzed for their viability by annexin V/ PI staining. (f) pNs were cultured $48 \mathrm{~h}$ with unstimulated p- or dCD3 ${ }^{-} \mathrm{CD} 56^{+}$spt and analyzed by flow cytometry. One representative experiment out of 7 performed. (g) pNs were cultured, for $48 \mathrm{~h}$, alone (gray bar; $n=10)$ or with spt obtained from unstimulated ( $n=7-9$ ) or IL2- or IL15-stimulated p- (white bars; $n=4-5$ ) or dCD3 ${ }^{-}$CD56 ${ }^{+}$cells (black bars; $n=5$ ) and analyzed. PI, propidium iodide.

(Figure 2c). We also assessed whether $\mathrm{dNs}$ were able to migrate in response to CXCL8 released by $\mathrm{dCD}^{-}{ }^{-} \mathrm{CD} 56^{+}$cells. As shown in Figure $2 \mathbf{d}, \mathrm{dCD}^{-}{ }^{-} \mathrm{CD}_{56}{ }^{+}$supernatants (spt) could induce a higher migration of $\mathrm{dNs}$ than $\mathrm{pCD} 3{ }^{-} \mathrm{CD}_{56}{ }^{+}$spt. In the presence of $\alpha$-CXCL $8 \mathrm{mAb}$ or CXCR1/CXCR2 inhibitor, the number of migrating dNs slightly decreased (Figure 2d). However, dNs, consistent with their low expression of CXCR1/ CXCR2 (Figure 2b), exhibited a lower capacity to migrate in response to $\mathrm{dCD}^{-}{ }^{-} \mathrm{CD}_{5}{ }^{+}$spt than $\mathrm{pNs}$ (Figure $2 \mathrm{c}$ and $\mathbf{d}$ ).

In order to assess whether $\mathrm{dCD}^{-} \mathrm{CD}^{-} 6^{+}$cells could influence neutrophil survival, $\mathrm{pNs}$ were co-cultured with $\mathrm{dCD}^{-} \mathrm{CD}^{-} 6^{+}$cells. As shown in Figure $\mathbf{2 e}, \mathrm{dCD} 3^{-}$ $\mathrm{CD}^{+} 6^{+}$cells induced a significant enhancement of $\mathrm{pN}$ survival (annexin V-negative cells) that was maintained also under transwell (TW) conditions or with the use of spt derived from unstimulated (Figure $2 \mathbf{e}$ and $\mathbf{f}$ ) or IL2- or IL15-stimulated $\mathrm{dCD}^{-} \mathrm{CD}^{-} 6^{+}$cells (Figure 2g). Similar results were obtained using the caspase-3 assay (Supplementary Figure S2a-b). Spt derived from unstimulated or cytokine-stimulated $\mathrm{pCD}^{-}{ }^{-} \mathrm{CD}^{+} 6^{+}$cells were used as control (Figure $\mathbf{2 f}$ and $\mathbf{g}$ and Supplementary Figure S2b). ${ }^{20}$ Taken together, these data indicate that soluble factors spontaneously released by $\mathrm{dCD}^{-} \mathrm{CD}^{-} 6^{+}$cells positively influence $\mathrm{pN}$ survival.

Different cytokines, including GM-CSF, IFN $\gamma$, and TNF, are known to promote neutrophil survival. ${ }^{22,36,37}$ Thus, we analyzed whether these cytokines were present in cell-free spt of unstimulated or cytokine-stimulated $\mathrm{d}$ - or $\mathrm{pCD}^{-}$ $\mathrm{CD}_{56}{ }^{+}$cells. Spt from unstimulated $\mathrm{dCD} 3^{-} \mathrm{CD}^{-} 6^{+}$cells contained high amounts of GM-CSF, that was further increased upon IL2 or IL15 stimulation (Figure 3a). In contrast, in spt 
a

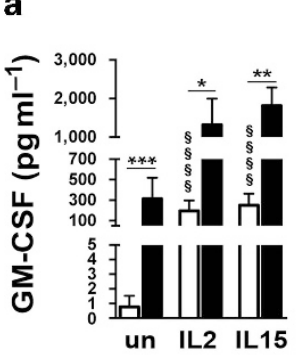

C

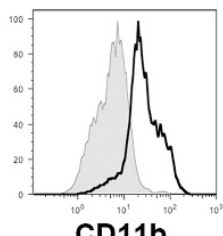

CD11b
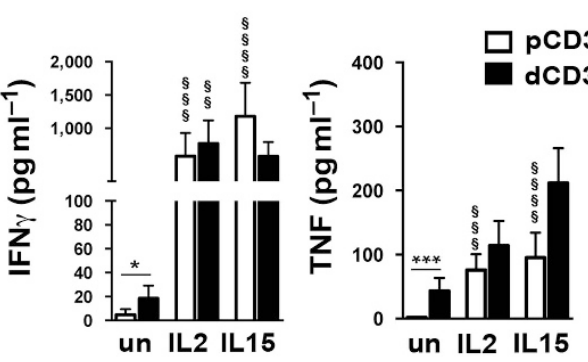

b

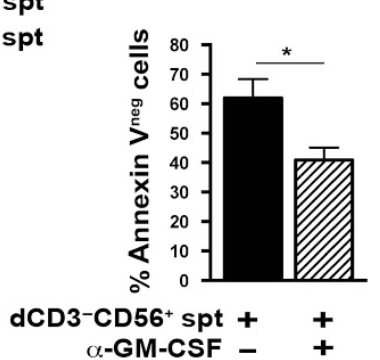

d

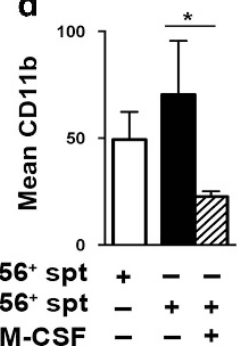

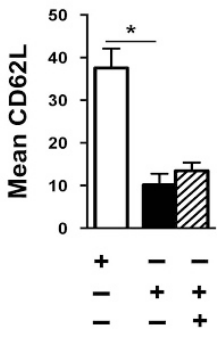

Figure 3 Role of decidual CD3 ${ }^{-} \mathrm{CD}_{5}{ }^{+}$-derived cytokines on neutrophil phenotype and survival. (a) Concentration of GM-CSF, IFN $\gamma$, and TNF $\left(\mathrm{pg} \mathrm{ml}{ }^{-1}\right) \pm$ s.e.m. in spt obtained from $\mathrm{p}$ - (white bars) or dCD3 ${ }^{-}$CD56 ${ }^{+}$(black bars) cells cultured, for $48 \mathrm{~h}$, in the absence or in the presence of IL2 or IL15 $(n=2-13)$. Statistical analysis was performed using Mann-Whitney test. $\left(^{*}\right)$ Indicates comparison between the two different cell subsets (p- vs. $\mathrm{d}-\mathrm{CD}^{-} \mathrm{CD}^{-} 6^{+}$) activated using the same stimulus, while (§) indicate comparison between stimulated and unstimulated cells within the same cell subset. When not indicated, data were not statistically significant. (b) Percentages of annexin V-negative \pm s.e.m. of pNs cultured, for $48 \mathrm{~h}$, with unstimulated $\mathrm{dCD}^{-}{ }^{-} \mathrm{CD}_{5}{ }^{+}$spt in the absence (black bars; $n=10$ ) or in the presence of neutralizing $\alpha$-GM-CSF Ab (stripped bars; $n=7$ ). Statistical analysis was performed using Mann-Whitney test. (c) Expression of CD11b and CD62L on pNs cultured, for $48 \mathrm{~h}$, with unstimulated p- (filled gray profile) or $\mathrm{dCD}^{-}{ }^{-\mathrm{CD}_{5}{ }^{+}}$spt (black line). One representative experiment out of four performed. (d) Statistical analysis of mean \pm s.e.m. of CD11b and CD62L on pNs cultured with unstimulated p- (white bars; $n=4-6$ ) or $\mathrm{dCD}^{-}{ }^{-} \mathrm{CD}_{5}{ }^{+}$spt (black bars; $n=4-6$ ) either in the absence or in the presence of neutralizing $\alpha$-GM-CSF Ab (stripped bars; $n=4$ ). Statistical analysis was performed using Mann-Whitney test. When not indicated, data were not statistically significant.

from $\mathrm{pCD} 3{ }^{-} \mathrm{CD}^{+}{ }^{+}$cells, GM-CSF was detectable only upon IL2 or IL15 stimulation (Figure 3a). Low amounts of IFN $\gamma$ and TNF were detected in unstimulated $\mathrm{d}-$ and $\mathrm{pCD} 3{ }^{-} \mathrm{CD} 56^{+}$cell spt, while both cytokines increased upon IL2 or IL15 stimulation (Figure 3a). As shown in Figure 3b, the percentage of annexin $\mathrm{V}$-negative $\mathrm{pNs}$ cultured with unstimulated $\mathrm{dCD} 3{ }^{-} \mathrm{CD} 56^{+}$spt, in the presence of neutralizing antiGM-CSF ( $\alpha$-GM-CSF) Ab, significantly decreased. We further investigated whether $\mathrm{dCD} 3{ }^{-} \mathrm{CD} 56^{+}$-derived GM-CSF could also influence the activation status of $\mathrm{pNs}$ (CD11b upregulation and $\mathrm{CD} 62 \mathrm{~L}$ downregulation ${ }^{20}$ ). Spt derived from unstimulated dCD $3{ }^{-} \mathrm{CD} 56^{+}$cells displayed higher ability to induce upregulation of $\mathrm{CD} 11 \mathrm{~b}$ and downregulation of $\mathrm{CD} 62 \mathrm{~L}$ compared with unstimulated $\mathrm{pCD} 3{ }^{-} \mathrm{CD} 56^{+}$spt (Figure 3c and d). However, only CD11b upregulation was slightly inhibited by neutralizing $\alpha$-GM-CSF Ab, while CD62L was not affected (Figure 3d).

\section{Decidual neutrophils produce heparin binding-epidermal} growth factor (HB-EGF)

In view of the relevant role of HB-EGF during pregnancy, ${ }^{13}$ we investigated whether $\mathrm{dNs}$ could be responsible, at least in part, for its production. As shown in Figure 4a, immunohistochemical analysis revealed that dNs expressed HB-EGF in situ (arrows in upper panel), while neutrophils present in other normal (spleen) and inflamed (gastritis) tissues were negative or poorly expressing HB-EGF (Figure $4 \mathbf{b}$ ). Consistently, neutrophils that have been freshly isolated from decidual tissues, but not pNs, were found to express HB-EGF mRNA (Figure 4c). As previous studies revealed that $\mathrm{pNs}$ exposed to GM-CSF could express HB-EGF mRNA, ${ }^{15}$ we analyzed whether $\mathrm{pNs}$ cultured for $2.5 \mathrm{~h}$ with spt derived from unstimulated $\mathrm{dCD}^{-} \mathrm{CD}^{-} 6^{+}$cells and IL15-stimulated pCD3 ${ }^{-} \mathrm{CD}_{56}{ }^{+}$cells (both containing high amounts of GM-CSF, as shown in Figure 3a) could induce HB-EGF mRNA accumulation in pNs. As shown in Figure 4d, HB-EGF mRNA levels increased in pNs in the presence of these spts and this effect was blocked by a neutralizing $\alpha$-GM-CSF Ab. In addition, we analyzed whether other transcripts were modulated in a GM-CSF-dependent manner. For such a purpose, we assessed the mRNA expression of IL1 receptor antagonist (IL1ra), in view of its role in trophoblast growth/ invasion and in the negative regulation of IL $1 \alpha$ and IL1 $\beta$ proinflammatory activity. ${ }^{31,32,38}$ In addition, its expression has been shown to be induced in neutrophils by GM-CSF. ${ }^{39} \mathrm{We}$ found that IL1ra mRNA expression was slightly higher in $\mathrm{dN}$ isolated ex vivo than in $\mathrm{pN}$ (Figure 4e). In addition, spt of unstimulated $\mathrm{dCD}^{-} \mathrm{CD}^{-} 6^{+}$or IL15-stimulated $\mathrm{pCD}^{-}$ 
a

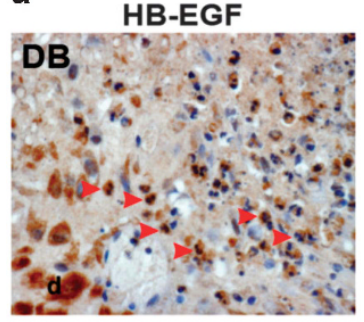

Negative control

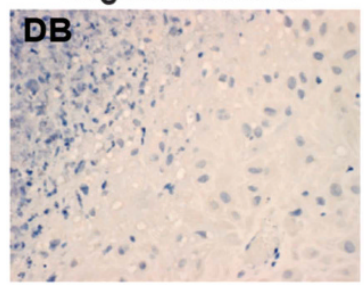

b

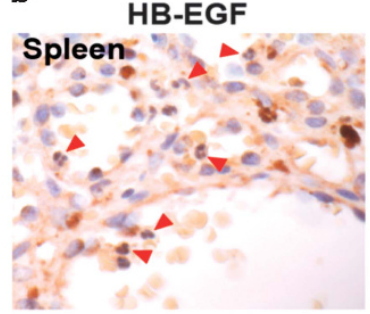

HB-EGF

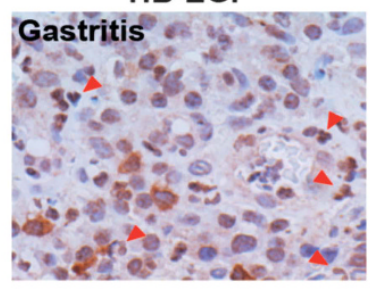

c
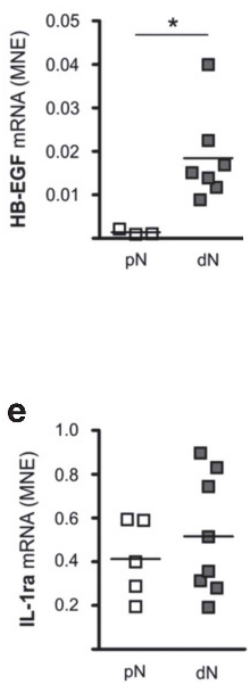

d

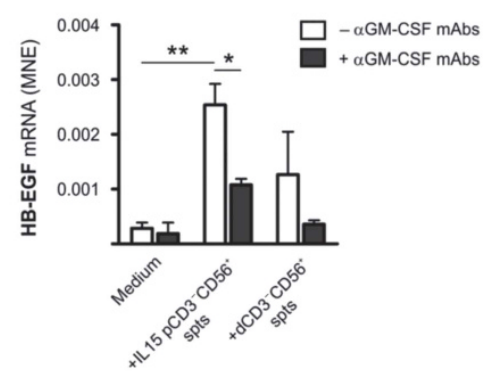

f

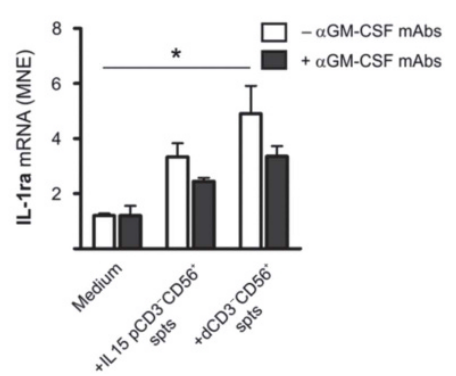

Figure 4 GM-CSF-dependent HB-EGF expression in decidual neutrophils. (a, b) Immunohistochemical analysis of HB-EGF. (a) DB, arrows indicate examples of $\mathrm{HB}-\mathrm{EGF}^{+}$polymorphonuclear neutrophils (upper panel). The lower panel shows DB tissue section stained with secondary antibody, as negative control. (b) Spleen (upper panel) and gastritis (lower panel) tissue, arrows indicate HB-EGF-negative neutrophils. (c, d) Levels of HB-EGF mRNA expression by (c) freshly purified pNs (white; $n=4$ ) or dNs (black; $n=7$ ) or by (d) pNs incubated for $2.5 \mathrm{~h}$ with medium alone or with spt derived from IL15-stimulated pCD3 ${ }^{-} \mathrm{CD}^{+}{ }^{+}$(as positive control) or unstimulated dCD3 ${ }^{-} \mathrm{CD} 6^{+}$cells, in the absence (white bars) or in the presence of $\alpha$-GMCSF Ab (black bars). (e, f) Levels of IL1 ra mRNA expression by (e) freshly purified pNs (white; $n=4$ ) or dNs (black; $n=7$ ) or by (f) pNs incubated for $2.5 \mathrm{~h}$ with medium alone or with spt derived from IL15-stimulated pCD3 ${ }^{-} \mathrm{CD}^{+} 6^{+}$(as positive control) or unstimulated dCD3 ${ }^{-} \mathrm{CD} 6^{+}$cells, in the absence (white bars) or in the presence of $\alpha$-GM-CSF Ab (black bars). (d, f) Bars indicate the MNE \pm s.e.m. from three independent experiments. When not indicated, data were not statistically significant. MNE, mean normalized expression.

$\mathrm{CD}^{+} 6^{+}$induced an upregulation of IL1ra mRNA that was partially inhibited by $\alpha$-GM-CSF Ab (Figure 4f). Altogether, these data suggest that GM-CSF released by $\mathrm{dCD}^{-}{ }^{-} \mathrm{CD} 56^{+}$ cells may induce neutrophils to express the mRNA for HB-EGF and IL1ra, two cytokines involved in neo-angiogenesis and blastocyst implantation.

Role of decidual ILC3 in neutrophil migration and survival We have recently shown that $\mathrm{NCR}^{+}$ILC3 are present in human decidua during the first trimester of pregnancy. ${ }^{11}$ Although $\mathrm{NCR}^{+}$ILC3 are included in $\mathrm{dCD}^{-}{ }^{-} \mathrm{CD}_{5} 6^{+}$cell fraction, they can be distinguished from "conventional" dNK cells (CD3 ${ }^{-}$ $\left.\mathrm{CD} 56^{+} \mathrm{CD} 94^{+} \mathrm{CD}^{+}\right)$on the basis of their phenotype $\left(\mathrm{CD}{ }^{-}\right.$ $\mathrm{CD} 56{ }^{+} \mathrm{CD} 94^{-} \mathrm{CD} 127^{+} \mathrm{CD} 117^{+} \mathrm{NKp} 44^{+} \mathrm{CD} 9^{-} \mathrm{ROR} \gamma \mathrm{t}^{+}$). Decidual tissues contain different proportions of $\mathrm{NCR}^{+} \mathrm{ILC}^{+}$ and $\mathrm{dNs}$ in the total $\mathrm{CD}_{4} 5^{+}$decidual cells (Figure 5a). However, $\mathrm{NCR}^{+}$ILC3 (identified by the co-expression of $\mathrm{NKp} 44$ and ROR $\gamma \mathrm{t}$ ) (Figure 5b) were detected in proximity of $\mathrm{CD}^{+} 5^{+} \mathrm{dNs}$ (mean distance $41 \pm 9 \mu \mathrm{m}$ ) (Figure 5c).

As Magri et al. ${ }^{40}$ reported that splenic $\mathrm{NCR}^{+} \mathrm{ILC}$ can mediate neutrophil activation via GM-CSF, we investigated whether decidual $\mathrm{NCR}^{+}$ILC3 and/or dNK cells could be responsible for GM-CSF production. To this end, decidual infiltrating lymphocytes were triggered with different stimuli and the cytokines produced by either $\mathrm{NCR}^{+}$ILC3 or $\mathrm{dNK}$ cells were analyzed. Decidual NCR ${ }^{+}$ILC3 spontaneously produced GM-CSF and TNF. Moreover, the percentages of cytokinepositive cells increased upon IL15 or PMA/Ionomycin/IL23 $(\mathrm{P} / \mathrm{I} / 23)$ or $\mathrm{P} / \mathrm{I}$ stimulation (Figure 5d). On the other hand, dNK cells expressed GM-CSF, IFN $\gamma$, and TNF only upon P/I/23 or P/I stimulation (Figure 5d). Similar results were obtained by the analysis of spt of sorted NCR ${ }^{+}$ILC3 or dNK cells (Supplementary Figure S3a). Notably, only $\mathrm{NCR}^{+}$ILC3 produced IL22 upon P/I/23 stimulation (Supplementary Figure S3a-b). In order to obtain further evidence that GM-CSF produced by $\mathrm{NCR}^{+}$ILC3 was involved in neutrophil survival, in a first set of experiments, $\mathrm{dCD}^{-}{ }^{-} \mathrm{CD} 56^{+}$cells were depleted, by cell sorting, of the $\mathrm{NCR}^{+}$ILC3 fraction and co-cultured with pNs. As shown in Supplementary Figure S3c, only unfractionated $\mathrm{dCD} 3{ }^{-} \mathrm{CD} 6^{+}$cells supported $\mathrm{pN}$ viability, thus suggesting a role of $\mathrm{NCR}^{+}$ILC3 in neutrophil survival. Indeed, sorted $\mathrm{NCR}^{+} \mathrm{ILC} 3$, but not dNK cells, increased neutrophil survival and induced $\mathrm{CD} 11 \mathrm{~b}$ upregulation (Figure 5e and $\mathrm{f}$ and Supplementary Figure S3d). Moreover, in the presence of neutralizing $\alpha$-GM-CSF Ab, neutrophil survival was significantly inhibited (Figure 5e), while upregulation of CD11b was only slightly affected (Figure 5f and Supplementary Figure S3d). In addition, $\mathrm{NCR}^{+} \mathrm{ILC} 3$, but not dNK cells, spontaneously produced CXCL8 that significantly increased upon $\mathrm{P} / \mathrm{I} / 23$ stimulation (Figure $5 \mathrm{~g}$ and 
a

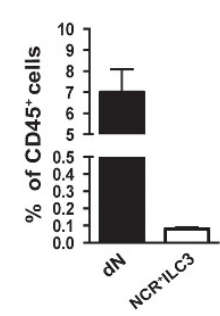

b

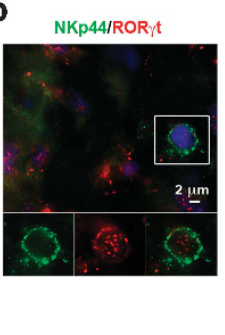

C. NKp44

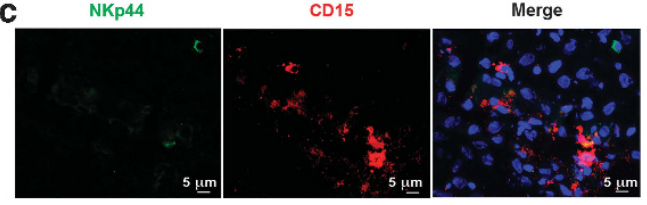

NKp44

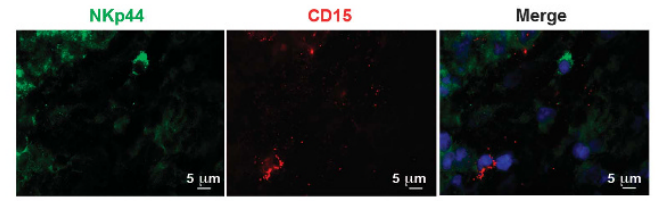

d

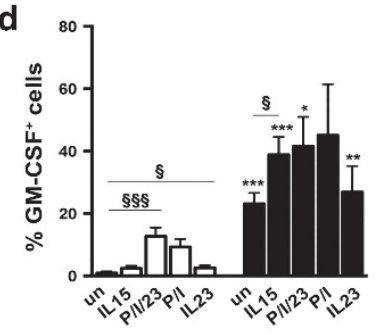

e

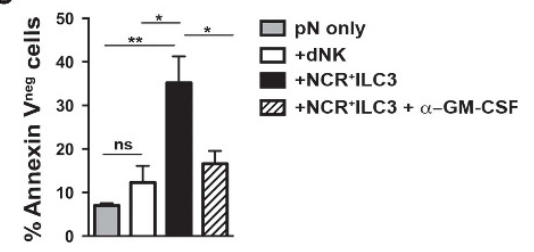

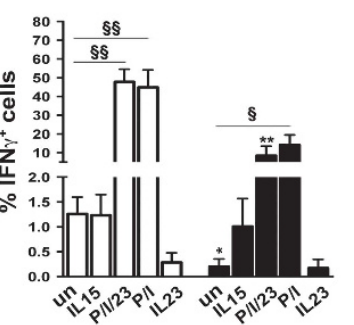

f

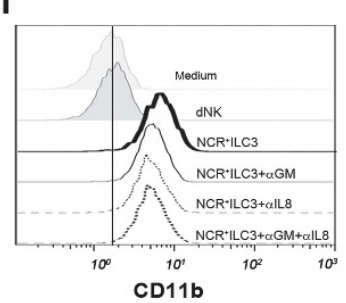

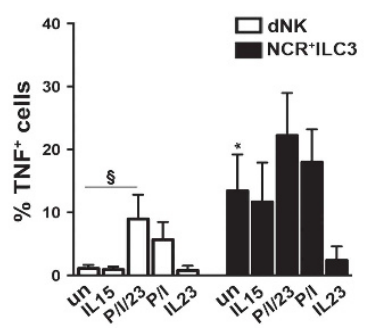

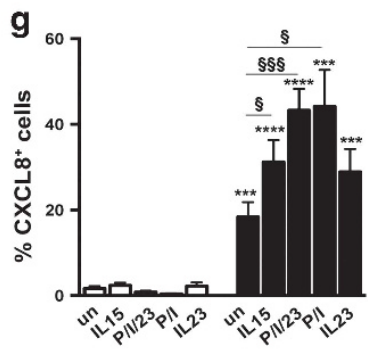

h

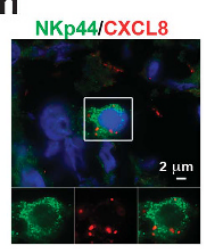

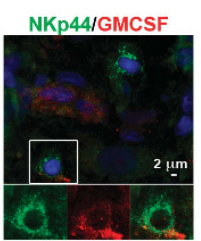
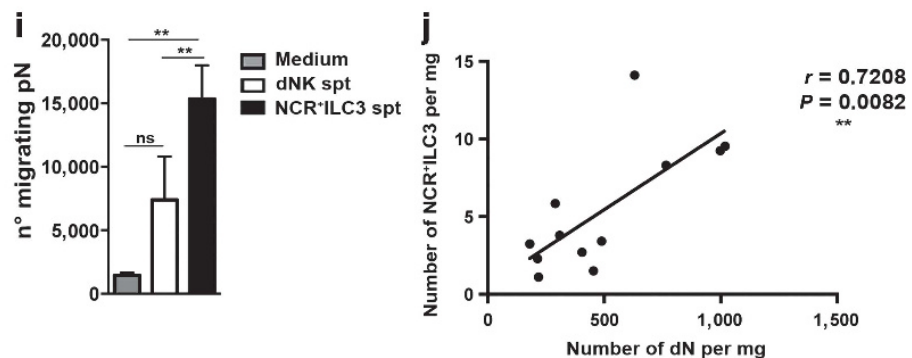

Figure $5 \mathrm{NCR}^{+}$ILC3 promote neutrophil migration and survival via production of CXCL8 and GM-CSF. (a) Frequency \pm s.e.m. of dNs and NCR ${ }^{+}$ ILC3 among total decidua-infiltrating $\mathrm{CD}_{4} 5^{+}$cells isolated from 12 different patients. (b, c) Staining of frozen sections of decidual tissues. (b) NKp44 (green) and ROR $\gamma \mathrm{t}$ (red) staining. White line $=2 \mu \mathrm{m}$, square indicate the cells that co-expressed both markers. (c) NKp44 (green) and CD15 (red) staining. White line $=5 \mu \mathrm{m}$, mean distance was $41 \pm 9 \mu \mathrm{m}$. (d) DILs were stimulated over night with the indicated stimuli and analyzed by flow cytometry for the expression of the indicated cytokines after gating on $\mathrm{Lin}^{-}\left(\mathrm{CD} 34^{-} \mathrm{CD} 14^{-} \mathrm{CD}_{19}^{-} \mathrm{CD}^{-}\right) \mathrm{CD}^{-} 6^{+} \mathrm{CD}^{-} 4^{+} \mathrm{CD} 117^{-} \mathrm{NKp}^{-} 4^{-} \mathrm{CD} 9^{+}$dNK cells and $\mathrm{Lin}^{-} \mathrm{CD} 6^{+} \mathrm{CD} 4^{-} \mathrm{CD} 117^{+} \mathrm{NKp}_{4}{ }^{+} \mathrm{NCR}^{+}$ILC3 cells. Mean \pm s.e.m. of percentage of positive cells $(n=5-19)$. Statistical analysis was performed using Mann-Whitney test. $\left(^{\star}\right)$ Indicates comparison between the two different cell subsets (dNK vs. NCR ${ }^{+}$ILC3) activated using the same stimulus, while (\$) indicate comparison between stimulated and unstimulated cells within the same cell subset. When not indicated, data were not statistically significant. (e) pNs were co-cultured with sorted dNK cells (white bar) or NCR ${ }^{+}$ILC3 (10:1 ratio) in the absence (black bar) or in the presence of blocking $\alpha$-GM-CSF $\mathrm{Ab}$ (stripped bar). Percentage of Annexin $\mathrm{V}$ negative neutrophils \pm s.e.m. $(n=4-6)$. Statistical analysis was performed using Mann-Whitney test. (f) One representative experiment of CD11b expression $(n=5-7)$. (g) DILs were stimulated ex vivo with indicated stimuli and analyzed gating on dNK cells and NCR ${ }^{+}$ILC3. Percentage of CXCL8 positive cells \pm s.e.m. $(n=7-12)$. Statistical analysis was performed using Mann-Whitney test. $\left(^{*}\right)$ Indicates comparison between the 2 different cell subsets (dNK vs. NCR ${ }^{+}$ILC3) activated using the same stimulus, while (\$) indicate comparison between stimulated and unstimulated cells within the same cell subset. When not indicated, data were not statistically significant. (h) Staining for NKp44 (green) and CXCL8 or GM-CSF (red) on frozen sections of decidual tissues. White line $=2 \mu \mathrm{m}$, square indicate the cells that co-expressed both markers. (i) Number of migrating $\mathrm{pN}$ (mean \pm s.e.m., $n=4-11$ ) upon incubation with spt derived from IL15-stimulated dNK cells or NCR ${ }^{+}$ILC3. $^{2}$ Statistical analysis was performed using Mann-Whitney test. (j) Correlation between the absolute number of NCR ${ }^{+}$ILC3 (identified as $\mathrm{CD} 45^{+} \mathrm{Lin}^{-} \mathrm{CD}_{6}{ }^{+} \mathrm{CD} 94^{-} \mathrm{CD} 117^{+} \mathrm{CD}_{127}{ }^{+}$) and dNs (identified as CD45 ${ }^{+} \mathrm{CD}^{-}{ }^{-} \mathrm{CD} 56{ }^{-} \mathrm{CD}_{16}{ }^{+} \mathrm{CD} 14^{\text {dim }} \mathrm{CD}_{15}{ }^{+} \mathrm{CD} 6 \mathrm{~b}^{+}$) per mg of tissues among total decidua-infiltrating $\mathrm{CD} 45^{+}$cells isolated from 12 different patients. 
Supplementary Figure S3a). Notably, $\mathrm{NCR}^{+}$ILC3, identified as $\mathrm{NKp} 44^{+}$cells, expressed CXCL8 and GM-CSF in vivo (Figure 5h). However, $\mathrm{NCR}^{+} \mathrm{ILC}$-derived CXCL8 did not affect $\mathrm{CD} 11 \mathrm{~b}$ upregulation in neutrophils, as revealed by the use of neutralizing $\alpha$-CXCL8 Ab (Figure $5 \mathbf{f}$ and Supplementary Figure S3d). As CXCL8 is also a potent neutrophil chemotactic factor, we investigated whether $\mathrm{NCR}^{+}$ILC3-derived CXCL8 could influence the recruitment of neutrophils. Indeed, CXCL8 present in $\mathrm{NCR}^{+}$ILC3 spt induced $\mathrm{pN}$ migration (Figure 5i) that was inhibited by CXCR1/CXCR2 inhibitor (Supplementary Figure S3e). Similarly, dNs migrated in response to $\mathrm{NCR}^{+}$ILC3 spt and migration was only slightly decreased in the presence of CXCR1/CXCR2 inhibitor (Supplementary Figure S3e). These results were in line with the low expression of CXCR1/CXCR2 on dNs (Figure 2b). Notably, although other cell types in decidual microenvironment may represent a suitable source of CXCL8, the number of infiltrating neutrophils directly correlated with the number of $\mathrm{dNCR}^{+}$ILC3 (Figure $5 \mathbf{j}$ ). The present data not only indicate that, within $\mathrm{dCD}^{-}{ }^{-} \mathrm{CD} 56^{+}$cells, GM-CSF and CXCL8 production is confined to $\mathrm{NCR}^{+} \mathrm{ILC} 3$, but also suggest that $\mathrm{NCR}^{+} \mathrm{ILC} 3$ may be involved in recruiting neutrophils and in extending their survival.

\section{$\mathrm{NCR}^{+}$ILC3 induce HB-EGF and IL1ra mRNA expression in neutrophils}

As $\mathrm{NCR}^{+}$ILC3 can spontaneously produce GM-CSF, we investigated whether $\mathrm{NCR}^{+}$ILC3-derived GM-CSF was able to induce HB-EGF mRNA expression in pNs. To this end, $\mathrm{pN}$ were incubated for $2.5 \mathrm{~h}$ with spt derived from sorted $\mathrm{NCR}^{+}$ ILC3 or dNK cells. As shown in Figure 6a, pN cultured with $\mathrm{NCR}^{+}$ILC3 spt, but not with dNK spt, expressed high levels of HB-EGF mRNA. This effect was inhibited in the presence of neutralizing $\alpha$-GM-CSF Ab. In addition, we assessed whether also the levels of IL1ra mRNA were influenced by GM-CSF released from $\mathrm{NCR}^{+}$ILC3. Indeed, the expression of IL1 ra mRNA increased in $\mathrm{pNs}$ cultured with spt derived from $\mathrm{NCR}^{+}$ILC3, but not from dNK cells. Notably, this effect was completely blocked in the presence of neutralizing $\alpha$-GM-CSF $\mathrm{Ab}$ (Figure 6b).

\section{DISCUSSION}

In this study, we show that neutrophils are present during the first trimester of pregnancy in human decidua in particular, in $\mathrm{DB}$, i.e., an area mainly involved in tissue remodeling and in physiological decidual implant reaction. Furthermore, neutrophils are more represented in normal pregnancy than in spontaneous miscarriages. Functionally, dNs display a significantly higher resistance to apoptosis than $\mathrm{pNs}$ in vitro, do not exert a suppressive activity, and express fibro/angiogenic factors, thus suggesting that they may be involved in the induction/maintenance of pregnancy. We also show that $\mathrm{NCR}^{+}$ILC3 are present in decidual tissue where they produce CXCL8 and GM-CSF, ${ }^{16}$ suggesting that they may have a role in neutrophil recruitment and survival. In addition, we found that $\mathrm{NCR}^{+}$ILC3-derived GM-CSF induces the expression of
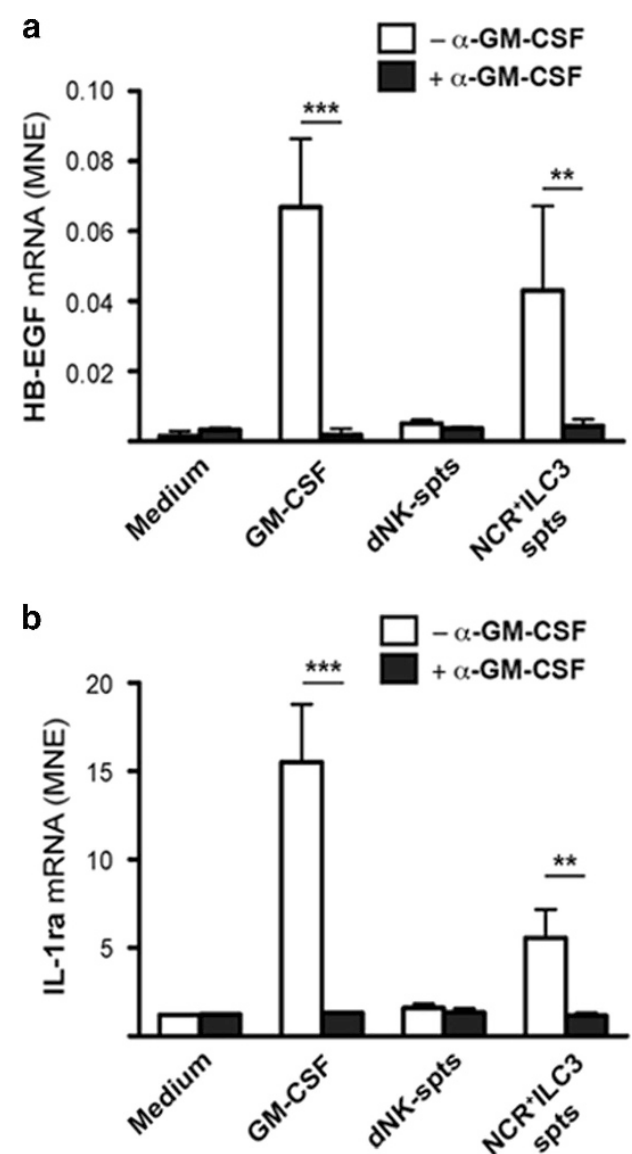

Figure $6 \mathrm{NCR}^{+} \mathrm{ILC3}$, but not dNK cells, induce HB-EGF and IL1ra expression in neutrophils via GM-CSF production. (a, b) Expression of HB-EGF (a) or IL1 ra (b) mRNA in pNs incubated $2.5 \mathrm{~h}$ with $10 \mathrm{ng} \mathrm{ml}^{-1}$ GM-CSF or spt derived from IL15-stimulated dNK cells or NCR ${ }^{+}$ILC3, in the absence (white bars) or in the presence of neutralizing $\alpha$-GM-CSF $\mathrm{Ab}$ (black bars). Bars indicate MNE \pm s.e.m. from three independent experiments. When not indicated, data were not statistically significant.

both of HB-EGF and IL1ra in neutrophils (N). Notably, both factors are involved in angiogenesis and trophoblast growth/invasion. ${ }^{13,14,31,32}$ Because, in normal pregnancy, we also found the direct correlation between the numbers of neutrophils and $\mathrm{NCR}^{+}$ILC3-infiltrating decidual tissues, it is possible to speculate that a cross talk may take place between these two cell types contributing to a successful pregnancy. Our data confirm and extend a recent study revealing the presence of neutrophils during the trimester of pregnancy, where they would favor spiral artery remodelling. ${ }^{16}$ The presence of neutrophils in decidua, during the first trimester of pregnancy, is consistent with the notion that a successful pregnancy requires an early "inflammatory" phase, which induces tissue remodeling and trophoblast migration necessary for implantation, and a late "regulatory" phase, occurring during the second trimester, that prevents fetal rejection and maintains pregnancy. ${ }^{41,42}$

It is known that neutrophils contribute to the regulation of innate/adaptive immune responses thanks to their ability to release cytokines and to interact with other cell types including 
macrophages, dendritic cells, NK cells, B and T lymphocytes, and even mesenchymal cells. ${ }^{18,20,24-30}$ Recent studies revealed that cytokines released by NK cells may induce neutrophil activation, expression of activation markers, and production of cytokines and angiogenic factors. ${ }^{20}$ Under appropriate experimental conditions, NK cells have been also shown to induce neutrophil apoptosis. ${ }^{29}$ Conversely, neutrophils may affect NK cell proliferation, cytolytic activity, cytokine production, and survival via contact-dependent or contact-independent mechanisms. $^{20}$

$\mathrm{NCR}^{+}$ILC3 were originally identified as a subset of ILC distinct from NK cells, although sharing with these cells phenotypic features, such as the expression of NKp44 and NKp46 activating receptors. $\mathrm{NCR}^{+}$ILC3 were first detected and characterized in intestinal lamina propria, tonsils, and skin. ${ }^{1,12,43,44}$ Recently, we identified $\mathrm{NCR}^{+}$ILC3 (CD3 ${ }^{-}$ $\mathrm{CD}_{6}{ }^{+} \mathrm{CD}_{4}{ }^{-} \mathrm{CD} 127^{+} \mathrm{CD} 117^{+} \mathrm{NKp} 44^{+}$) and LTi-like cells $\left(\mathrm{CD} 3{ }^{-} \mathrm{CD} 6^{-} \mathrm{CD}^{-} 4^{-} \mathrm{CD} 127^{+} \mathrm{CD}_{117^{+}}\right)$in human decidua. In decidual tissues, $\mathrm{NCR}^{+}$ILC3 are present in small proportions if compared with $\mathrm{dNK}$ cells $\left(\mathrm{CD} 3{ }^{-} \mathrm{CD} 56^{+} \mathrm{CD}^{-} 4^{+}\right)$, but similar to those described in other tissues. ${ }^{11}$ One may argue that, given their small numbers, $\mathrm{NCR}^{+}$ILC3 are unlikely to have a major functional role in decidua. However, here we show that, within $\mathrm{dCD}^{-} \mathrm{CD}^{-} 6^{+}$cells, the production of key cytokines such as CXCL8 and GM-CSF is virtually confined to the $\mathrm{NCR}^{+}$ILC3 subset. Magri et al. ${ }^{40}$ showed that spleen $\mathrm{NCR}^{+}$ILC3, thanks to the release of GM-CSF, could induce neutrophils to amplify the responses of marginal zone B cells. We found that $\mathrm{dNs}$ localize in proximity of $\mathrm{NCR}^{+} \mathrm{ILC} 3$, thus suggesting possible functional interactions. Moreover, our data suggest that decidual $\mathrm{NCR}^{+}$ILC3 may have an important role in neutrophil recruitment and survival, thanks to their spontaneous production of CXCL8 and GM-CSF, respectively. In addition, cytokine expression was further increased upon stimulation with IL15, a cytokine physiologically present in the decidual microenvironment. ${ }^{45}$ Furthermore, it has been reported that reduced $\mathrm{N}$ recruitment in decidual tissue in pregnant Rag2 ${ }^{-1-}$ IL $2 r \gamma^{-1-}$ mice may be consequent to the absence of NK cells. ${ }^{16}$ Of note, Rag $2^{-/-} I l 2 r \gamma^{-/-}$mice also display a defective ILC3 development. ${ }^{46}$ Thus, an inadequate $\mathrm{N}$ recruitment may reflect a reduction/absence of ILC3 in decidua. Further studies are required to elucidate this issue.

Surprisingly, dNK cells, originally thought to be the main producers of CXCL8 and GM-CSF, ${ }^{8}$ did not seem to spontaneously produce relevant amounts of these two cytokines. Therefore, in view of the relative abundance of dNK cells in decidual tissues, one may ask what is their functional role. First, we cannot exclude that dNK cells may release CXCL8 and GM-CSF upon triggering with still undefined stimuli present in decidual microenvironment. Second, they have been shown to release factors (e.g., CXCL10) involved in trophoblast migration and placentation. ${ }^{8,9}$ Third, dNK cells have been shown to functionally interact with peculiar $\mathrm{CD} 14^{+}$myeloid cells and this cross talk results in the expansion of regulatory $\mathrm{T}$ cells, thought to have a central role in fetomaternal tolerance. ${ }^{10}$ Finally, dNK cells express killer immunoglobulin-like receptors that can interact with HLA-C present on fetal trophoblast; these interactions regulate trophoblast migration, placentation, and fetal growth. ${ }^{47}$ Regarding LTi-like cells, preliminary experiments revealed that, in addition to IL17 and TNF, they also produced GM-CSF and CXCL8 (though in lower amounts compared with $\mathrm{NCR}^{+}$ILC3) (our unpublished observations and ${ }^{11}$ ). These data suggest that also LTi-like cells may participate in functional interactions with neutrophils.

During the early phases of pregnancy, an appropriate balance between inflammation and tolerance is essential for successful implantation. $^{41,42}$ In this context, our present data may contribute to shed light on the cellular and molecular mechanisms occurring in decidual tissues during the early phases of pregnancy. Accordingly, $\mathrm{NCR}^{+} \mathrm{ILC} 3$ resident in decidual tissues would mediate neutrophil migration and increase their resistance to apoptosis. Remarkably, we also show that $\mathrm{NCR}^{+}$ILC3-derived GM-CSF induces $\mathrm{N}$ to express $\mathrm{HB}$ EGF, which regulates endometrium/blastocyst interactions and promotes angiogenesis at the fetomaternal interface. ${ }^{13,14}$ Although the source of HB-EGF during pregnancy has not been identified so far, our data suggest that dNs may represent at least one of the cell types involved HB-EGF production. Moreover, neutrophils also express IL1 ra that, besides its ability to dampen excessive inflammatory responses by blocking IL $1 \alpha$ and IL1 $\beta$, also induces trophoblast invasion. ${ }^{31,32,38}$ It would be interesting to clarify whether $\mathrm{dNs}$ produce these factors also during the second trimester of pregnancy.

In conclusion, in the present study, we identified $\mathrm{N}$ and $\mathrm{NCR}^{+}$ILC3 as possible players in the early phases of pregnancy. Thus, it is possible to speculate that altered numbers and function of $\mathrm{NCR}^{+}$ILC3 and/or an impaired recruitment of neutrophils may be responsible of pregnancy failure.

\section{METHODS}

Isolation of decidual and peripheral blood cells. We obtained decidua samples at 9-12 weeks of gestation from singleton pregnancies of mothers requesting termination of pregnancy for social reasons at AOU San Martino-IST (Genoa, Italy). The relevant institutional review boards approved the study and all patients gave their written informed consent according to the Declaration of Helsinki. We isolated cell suspensions from decidual tissue with GentleMacs (Miltenyi Biotec, Bergisch Gladbach, Germany) and cells were then filtered as previously described. ${ }^{34}$ The cellular suspension was directly analyzed by flow cytometry (to analyzed $\mathrm{dNs}$ and $\mathrm{NCR}^{+}$ILC3 and their relative proportion) or decidua-infiltrating lymphocytes, peripheral blood mononuclear cells and decidual (d) or peripheral (p) neutrophils were isolated by Fycoll (Cedarlane, Burlington, Ontario, Canada) gradient centrifugation. Highly purified neutrophils ( $>98 \%$ pure) were obtained from granulocyte sediment using specific lysis buffer and then EasySep positive selection kit CD66b (StemCell technologies, Vancouver, British Columbia, Canada) as previously described. ${ }^{37}$ LD-dNs were obtained from mononuclear cell fraction after Ficoll gradient centrifugation and purified using EasySep positive selection kit CD66b. Cell purity was determined by flow cytometry. decidual infiltrating lymphocytes were analyzed by flow cytometry or isolated (NK isolation kit II from Miltenyi Biotec) to obtain $\mathrm{dCD}^{-}{ }^{-} \mathrm{CD} 6^{+}$cells ( $>98 \%$ pure). $\mathrm{pCD}^{-}{ }^{-} \mathrm{CD} 56^{+}$cells were isolated (with NK isolation kit II from Miltenyi Biotec or with RosetteSep from StemCell technologies) from peripheral blood mononuclear cells (>98\% pure). 
$\mathrm{dNK}$ cells $\left(\mathrm{CD} 3{ }^{-} \mathrm{CD}_{6}{ }^{+} \mathrm{CD} 94^{+} \mathrm{CD} 127^{-} \mathrm{CD} 117^{-} \mathrm{CD}^{+}\right)$and $\mathrm{NCR}^{+} \mathrm{ILC}_{3}\left(\mathrm{CD} 3{ }^{-} \mathrm{CD}_{56}{ }^{+} \mathrm{CD} 94^{-} \mathrm{CD}_{2} 27^{+} \mathrm{CD} 117^{+} \mathrm{NKp} 44^{+} \mathrm{CD} 9^{-}\right)$ were sorted accordingly to their phenotype using FACSAria (BD Bioscience, San Jose, CA), purity was routinely $>99 \%$.

Flow cytometry analyses and monoclonal antibodies. Cells were stained with the following monoclonal antibodies: CD66abce-APC, CD11b-APC Vio770, CD14-PE Vio770, CD14-FITC, CD16-FITC, CD15-PE, CD117-APC, and CD9-PE purchased from Miltenyi; CD45-APC, CD127-Brillant Violet, CD94-FITC, CD117-PerCP Cy5.5, and CD127-PerCP Cy5.5 purchased from BioLegend, (San Diego, CA); CD62L-PE, IFN $\gamma$-Alexa Fluor647, GM-CSF-PE purchased from BD Bioscience; CD3-ECD, CD14-ECD, CD56-PC7, CD34-PE purchased from IL-Beckman Coulter (Brea, CA); NKp44APC, TNF-eFluor450, and IL-22-PE purchased from eBioscience (San Diego, CA); CXCL8-PE, CXCR1-PE, and CXCR2-PE purchased from R\&D System (Minneapolis, MN); Live/dead fixable aqua dead purchased from Invitrogen/Molecular Probes (Carlsbad, CA). For cytokine detection, decidual infiltrating lymphocytes or sorted cells were stimulated as indicated in the results section in the presence of $25 \mathrm{ng} \mathrm{ml}^{-1}$ PMA (Sigma-Aldrich, St Louis, MO), $1 \mu \mathrm{g} \mathrm{ml}^{-1}$ Ionomycin (Sigma), and $50 \mathrm{ng} \mathrm{ml}^{-1}$ IL23 (Miltenyi) or $10 \mathrm{ng} \mathrm{ml}^{-1}$ IL15 (Miltenyi) or $100 \mathrm{U} \mathrm{ml}^{-1}$ IL2 (Peprotech, Rocky Hill, NJ), either in the presence or in the absence of GolgiStop (BD). After $18 \mathrm{~h}$ of stimulation, supernatants (spt) were harvested or cells were stained for surface markers, fixed, and permeabilized with Cytofix/Cytoperm and with Perm/Wash (BD), respectively, according to the manufacturer's instructions. For intracellular detection of cytokines, cells were gated as: $\left(\mathrm{CD} 3{ }^{-} \mathrm{CD} 14^{-} \mathrm{CD} 56^{+} \mathrm{CD} 94^{-} \mathrm{CD} 117^{+} \mathrm{NKp} 44^{+}\right) \mathrm{NCR}^{+} \mathrm{ILC} 3$ or $\left(\mathrm{CD} 3{ }^{-} \mathrm{CD} 56^{+} \mathrm{CD} 94^{+} \mathrm{CD} 117^{-} \mathrm{NKp} 44^{-}\right) \mathrm{dNK}$ cells and analyzed on Gallios Flow Cytometer (Beckman Coulter) or MACSQuant Analyzer (Miltenyi Biotec). Data analysis was carried out using FlowJo software (TreeStar, Ashland, OR).

Co-culture experiments. We obtained the spt from $\mathrm{p}$ - or $\mathrm{dCD} 3^{-}$ $\mathrm{CD}^{+} 6^{+}$or sorted $\mathrm{dNK}$ or $\mathrm{NCR}^{+}$ILC3 plated at $5 \times 10^{6}$ cells ml $\mathrm{ml}^{-1}$ concentration after culture for $24 \mathrm{~h}$ in the absence or in the presence of cytokines $\left(10 \mathrm{ng} \mathrm{ml}^{-1} \mathrm{IL} 15\right.$ or $100 \mathrm{U} \mathrm{ml}^{-1}$ IL2). After isolation, pNs or dNs were suspended in RPMI 1640 medium supplemented with $10 \%$ low endotoxin fetal bovine serum $\left(<0,5 \mathrm{EU} \mathrm{ml}^{-1}\right.$, Lonza, Walkersville, $\mathrm{MD}$ ) in polypropylene tube (BD). Neutrophils were cocultured, for $48 \mathrm{~h}$, with p- or $\mathrm{dCD}^{-}{ }^{-} \mathrm{CD}_{5} 6^{+}$cells or $\mathrm{NCR}^{+} \mathrm{ILC} 3$ depleted $\mathrm{dCD}^{-}{ }^{-} \mathrm{CD} 56^{+}$cells (at 1:5 ratio) or with p- or dCD3 $\mathrm{CD} 6^{+}$-derived spt and for $24 \mathrm{~h}$, with sorted dNK cells or $\mathrm{NCR}^{+}$ILC3 (at 10:1 ratio). Experiments were performed in the presence or in the absence of transwell chamber (Corning Costar, Tewksbury, MA). For $\mathrm{T}$-cell proliferation assay, $\mathrm{LD}$-dNs or ND-dNs were used as stimulators and carboxyfluorescein succinimidyl ester-labeled $\mathrm{T}$ cells as responders. Experiments were performed in the presence of anti-CD3/CD28 mAbs (Miltenyi) or IL15 $\left(10 \mathrm{ng} \mathrm{ml}^{-1}\right)$ at a neutrophils: $T$ ratio of $1: 5$. At day 7 of culture the proliferation of carboxyfluorescein succinimidyl ester-labeled T cells were analyzed by flow cytometry.

Determination of apoptosis. Apoptosis of $\mathrm{pNs}$ or $\mathrm{dNs}$ was evaluated after 24 or $48 \mathrm{~h}$ of co-culture with d- or $\mathrm{pCD} 6^{+} \mathrm{CD}^{-}$cells (at 1:5 ratio) or with sorted dNK cells or $\mathrm{NCR}^{+}$ILC3 (at 10:1 ratio), in the presence or in the absence of transwell. Similar experiments were performed using spt derived from unstimulated or IL2- or IL15stimulated $\mathrm{p}$ - or $\mathrm{dCD} 3{ }^{-} \mathrm{CD} 56^{+}$cells. All experiments were performed in the absence or in the presence of polyclonal neutralizing $\alpha$-human GM-CSF Ab $\left(10 \mu \mathrm{g} \mathrm{ml}^{-1}\right.$, R\&D System). For apoptosis analysis, annexin V-propidium iodide (eBioscience) or Vybrant FAM Caspase3 and -7 Assay Kit (Molecular Probes, Invitrogen, Eugene, OR) were used, according to the manufacturer's instructions.

Migration assay. Neutrophils were placed in the upper chamber of polycarbonate transwell ( 24 wells/plate or 96 well/plate) with a
$3 \mu \mathrm{m}$-pore membrane (Corning Costar). In the lower chamber, $600 \mu \mathrm{l}$ of unstimulated p- or $\mathrm{dCD}^{-} \mathrm{CD}^{-} 6^{+}$or $200 \mu \mathrm{l}$ of $\mathrm{NCR}^{+}$ILC3 derived spt were plated, in the absence or in the presence of neutralizing $\alpha$-human CXCL8 mAb $\left(2 \mu \mathrm{g} \mathrm{ml}^{-1}\right.$, R\&D System) or of CXCR1/ CXCR2 inhibitor (SCH563705, MedChem Express). After $30 \mathrm{~min}$ at $37^{\circ} \mathrm{C}$, the number of pNs or dNs that migrated across the filter was counted by MACSQuant Analyzer (Miltenyi Biotec). Data were analyzed with FlowJo software.

Supernatants analysis. CXCL8 levels were measured by competitive enzyme-linked immunosorbent assay technique using a commercially available enzyme-linked immunosorbent assay kit (R\&D System). GM-CSF, IFN- $\gamma$, TNF, IL22, and also CXCL8 in the cell-free supernatants were investigated using MILLIPLEX MAP magnetic bead-based multi-analyte panels evaluated using MagPix by Millipore (Merck Millipore, Darmstadt, Germany).

Immunohistochemical analysis. Decidual samples ( $7 \mu \mathrm{m}$ sections) were formalin-fixed and paraffin-embedded. Samples were de-paraffinized and subsequently exposed to $0.3 \%$ hydrogen peroxide-methanol solution to quench the endogenous peroxidase activity, prior to $30 \mathrm{~min}$ incubation with CD15 (Dako, Glostrup, Denmark). Then, horse radish peroxidase-conjugated goat anti-human anti-sera (Dako-Envision) and 3-amino-9-ethylcarbazole (Novocastra, Newcastle, UK) were added as previously described. ${ }^{48}$ The mean number/field ( \pm s.e.m.) of $\mathrm{CD}^{+} 5^{+}$cells was counted by three independent observers in five different fields for each patient. Staining with HB-EGF antibody (clone 125923, R\&D Systems) was performed as previously described. ${ }^{49}$ All incubations were performed at room temperature. An isotype-matched control $\mathrm{mAb}$ was used as negative control. Frozen sections of decidua were stained with anti-NKp44 (7A6 mouse IgG1), anti-ROR $\gamma \mathrm{t}$ (6F3.1 mouse IgG2a, Merck Millipore), anti-CD15 (clone MY-1, Abcam, Cambridge, UK), anti-CXCL8 (clone H-60, Santa Cruz, CA), and antiGM-CSF (rabbit anti-human GM-CSF, AbD Serotec, Oxfordshire, UK) followed by Alexa488 anti-mouse IgG1, Alexa 594 anti-rabbit or anti-mouse IgG2a (Life Technologies, CA). Nuclei were counterstained with DAPI.

Quantitative real-time reverse transcription-PCR. Real-time reverse transcription-PCR was performed exactly as described ${ }^{50}$ using gene-specific primer pairs (purchased from Invitrogen) available in the public database RTPrimerDB (http://medgen.ugent. be/rtprimerdb/) under the following entry codes: GAPDH (3539), HB-EGF (8165), and IL1RN (3544). Data were calculated by Q-Gene software (http://www.gene-quantification.de/download.html\#qgene) and expressed as mean normalized expression units after GAPDH normalization.

Statistical analysis. Statistical analysis was performed with Graphpad Prism (La Jolla, CA) software. For statistical analysis of immunohistochemistry, cytofluorimetric experiments and enzyme-linked immunosorbent assay were used non-parametric $t$-test. We performed statistical analysis of HB-EGF and IL1ra mRNA expression using Student's $t$-test, 2-tail distribution of unpaired samples (Figure 4c and e) or two-way analysis of variance with Bonferroni's post hoc test (Figure 4 and $f$ and Figure 6). $P$-value of less than 0.05 (* or $\S)$, less than 0.01 (** or $\S \S)$, less than 0.001 (*** or $\S \S)$, or less than 0,0001 (**** or $\S \S \S \S)$ was considered statistically significant. The analysis of correlation between $\mathrm{NCR}^{+}$ILC3 and $\mathrm{dN}$ was performed using linear regression test (Figure $5 \mathbf{j}$ ). In Figure 1i, Figure $3 \mathbf{a}$ and $\mathbf{d}$ and Figure 5d and $\mathrm{g}$ when not indicated, data were not statistically significant. Column bar graphs were plotted as mean and standard error of the mean (s.e.m.) or standard deviation (s.d.).

SUPPLEMENTARY MATERIAL is linked to the online version of the paper at http://www.nature.com/mi 


\section{ACKNOWLEDGMENTS}

This work was supported by grants awarded by Associazione Italiana Ricerca sul Cancro (AIRC): IG 2010 project n. 10225 (LM), IG 2014 project n. 15283 (LM), IG-15454 (MAC) and "Special Program Molecular Clinical Oncology 5x1000" project n. 9962 (LM). Ministero della Salute: RO strategici 8/07 (MCM). Progetto Ateneo 2013, University of Genoa (PV). DC and $\mathrm{AM}$ are the recipient of an AIRC fellowship.

\section{AUTHOR CONTRIBUTIONS}

DC designed the study, performed experiments, analyzed data, and wrote the manuscript; AM performed experiments, analyzed data, and wrote the manuscript; EM, analyzed data and wrote the manuscript; FL and FC performed the experiments; PO, EF, EM, and AZ performed immunohistochemical analysis; FC provided samples and assisted in experiments; PLV provided samples; LM, MAC, and MCM supervised the research and wrote the manuscript; PV designed the study, supervised, and performed experiments, analyzed data, and wrote the manuscript.

\section{DISCLOSURE}

The authors declared no conflict of interest.

c 2016 Society for Mucosal Immunology

\section{REFERENCES}

1. Spits, H. et al. Innate lymphoid cells-a proposal for uniform nomenclature. Nat. Rev. Immunol. 13, 145-149 (2013).

2. Montaldo, E., Vacca, P., Moretta, L. \& Mingari, M.C. Development of human natural killer cells and other innate lymphoid cells. Semin. Immunol. 26, 107-113 (2014).

3. Moretta, A., Bottino, C., Mingari, M.C., Biassoni, R. \& Moretta, L. What is a natural killer cell?. Nat. Immunol. 3, 6-8 (2002).

4. Erlebacher, A. Immunology of the maternal-fetal interface. Annu. Rev. Immunol. 31, 387-411 (2013).

5. Moffett-King, A. Natural killer cells and pregnancy. Nat. Rev. Immunol. 2, 656-663 (2002).

6. Vacca, P., Moretta, L., Moretta, A. \& Mingari, M.C. Origin, phenotype and function of human natural killer cells in pregnancy. Trends Immunol. 32, 517-523 (2011).

7. Chiossone, L. et al. In vivo generation of decidual natural killer cells from resident hematopoietic progenitors. Haematologica 99, 448-457 (2014).

8. Hanna, J. et al. Decidual NK cells regulate key developmental processes at the human fetal-maternal interface. Nat. Med. 12, 1065-1074 (2006).

9. Vacca, P. et al. Regulatory role of NKp44, NKp46, DNAM-1 and NKG2D receptors in the interaction between NK cells and trophoblast cells. Evidence for divergent functional profiles of decidual versus peripheral NK cells. Int. Immunol. 20, 1395-1405 (2008).

10. Vacca, P. et al. Crosstalk between decidual NK and CD14 + myelomonocytic cells results in induction of Tregs and immunosuppression. Proc. Natl. Acad. Sci. USA 107, 11918-11923 (2010).

11. Vacca, P. et al. Identification of diverse innate lymphoid cells in human decidua. Mucosal Immunol. 8, 254-264 (2015).

12. Cella, M. et al. A human natural killer cell subset provides an innate source of IL-22 for mucosal immunity. Nature 457, 722-725 (2009).

13. Jessmon, P., Leach, R.E. \& Armant, D.R. Diverse functions of HBEGF during pregnancy. Mol. Reprod. Dev. 76, 1116-1127 (2009).

14. Miyata, K., Yotsumoto, F., Nam, S.O., Kuroki, M. \& Miyamoto, S. Regulatory mechanisms of the HB-EGF autocrine loop in inflammation, homeostasis, development and cancer. Anticancer Res. 32, 2347-2352 (2012).

15. Vinante, F., Marchi, M., Rigo, A., Scapini, P., Pizzolo, G. \& Cassatella, M.A. Granulocyte-macrophage colony-stimulating factor induces expression of heparin-binding epidermal growth factor-like growth factor/diphtheria toxin receptor and sensitivity to diphtheria toxin in human neutrophils. Blood 94, 3169-3177 (1999).

16. Amsalem, $\mathrm{H}$. et al. Identification of a novel neutrophil population: proangiogenic granulocytes in second-trimester human decidua. J. Immunol. 193, 3070-3079 (2014).
17. Witko-Sarsat, V., Rieu, P., Descamps-Latscha, B., Lesavre, P. \& Halbwachs-Mecarelli, L. Neutrophils: molecules, functions and pathophysiological aspects. Lab. Invest. 80, 617-653 (2000).

18. Scapini, P. \& Cassatella, M.A. Social networking of human neutrophils within the immune system. Blood 124, 710-719 (2014).

19. Summers, C., Rankin, S.M., Condliffe, A.M., Singh, N., Peters, A.M. \& Chilvers, E.R. Neutrophil kinetics in health and disease. Trends Immunol. 31, 318-324 (2010).

20. Costantini, C., Micheletti, A., Calzetti, F., Perbellini, O., Pizzolo, G. \& Cassatella, M.A. Neutrophil activation and survival are modulated by interaction with NK cells. Int. Immunol. 22, 827-838 (2010).

21. Kim, D. \& Haynes, C.L. Neutrophil chemotaxis within a competing gradient of chemoattractants. Anal. Chem. 84, 6070-6078 (2012).

22. Tecchio, C., Micheletti, A. \& Cassatella, M.A. Neutrophil-derived cytokines: facts beyond expression. Front. Immunol. 5, 508 (2014).

23. Witko-Sarsat, V., Pederzoli-Ribeil, M., Hirsch, E., Sozzani, S. \& Cassatella, M.A. Regulating neutrophil apoptosis: new players enter the game. Trends Immunol. 32, 117-124 (2011).

24. Eken, C., Sadallah, S., Martin, P.J., Treves, S. \& Schifferli, J.A. Ectosomes of polymorphonuclear neutrophils activate multiple signaling pathways in macrophages. Immunobiology 218, 382-392 (2013).

25. Pelletier, M., Micheletti, A. \& Cassatella, M.A. Modulation of human neutrophil survival and antigen expression by activated CD4 + and CD8 + T cells. J. Leukoc. Biol. 88, 1163-1170 (2010).

26. Puga, I. et al. B cell-helper neutrophils stimulate the diversification and production of immunoglobulin in the marginal zone of the spleen. Nat. Immunol. 13, 170-180 (2012).

27. van Gisbergen, K.P., Sanchez-Hernandez, M., Geijtenbeek, T.B. \& van Kooyk, Y. Neutrophils mediate immune modulation of dendritic cells through glycosylation-dependent interactions between Mac-1 and DC-SIGN. J. Exp. Med. 201, 1281-1292 (2005).

28. Yang, C.W., Strong, B.S., Miller, M.J. \& Unanue, E.R. Neutrophils influence the level of antigen presentation during the immune response to protein antigens in adjuvants. J. Immunol. 185, 29272934 (2010).

29. Thoren, F.B. et al. Human NK Cells induce neutrophil apoptosis via an NKp46- and Fas-dependent mechanism. J. Immunol. 188, 1668-1674 (2012).

30. Bhatnagar, N. et al. Cytokine-activated NK cells inhibit PMN apoptosis and preserve their functional capacity. Blood 116, 13081316 (2010).

31. Abumaree, M.H., Chamley, L.W., Badri, M. \& El-Muzaini, M.F. Trophoblast debris modulates the expression of immune proteins in macrophages: a key to maternal tolerance of the fetal allograft?. J. Reprod. Immunol. 94, 131-141 (2012).

32. Librach, C.L. et al. Interleukin-1 beta regulates human cytotrophoblast metalloproteinase activity and invasion in vitro. J. Biol. Chem. 269, 17125-17131 (1994).

33. Musizzano, Y. \& Fulcheri, E. Decidual vascular patterns in first-trimester abortions. Virchows Arch. 456, 543-560 (2010).

34. Vacca, P. et al. Analysis of natural killer cells isolated from human decidua: Evidence that 2B4 (CD244) functions as an inhibitory receptor and blocks NK-cell function. Blood 108, 4078-4085 (2006).

35. Baggiolini, M., Walz, A. \& Kunkel, S.L. Neutrophil-activating peptide-1/ interleukin 8, a novel cytokine that activates neutrophils. J. Clin. Invest. 84, 1045-1049 (1989).

36. Colotta, F., Re, F., Polentarutti, N., Sozzani, S. \& Mantovani, A. Modulation of granulocyte survival and programmed cell death by cytokines and bacterial products. Blood 80, 2012-2020 (1992).

37. Pelletier, M. et al. Evidence for a cross-talk between human neutrophils and Th17 cells. Blood 115, 335-343 (2010).

38. Granowitz, E.V., Clark, B.D., Vannier, E., Callahan, M.V. \& Dinarello, C.A. Effect of interleukin-1 (IL-1) blockade on cytokine synthesis: I. IL-1 receptor antagonist inhibits IL-1-induced cytokine synthesis and blocks the binding of IL-1 to its type II receptor on human monocytes. Blood 79, 2356-2363 (1992).

39. McColl, S.R., Paquin, R., Menard, C. \& Beaulieu, A.D. Human neutrophils produce high levels of the interleukin 1 receptor antagonist in response to granulocyte/macrophage colony-stimulating factor and tumor necrosis factor alpha. J. Exp. Med. 176, 593-598 (1992). 
40. Magri, G. et al. Innate lymphoid cells integrate stromal and immunological signals to enhance antibody production by splenic marginal zone B cells. Nat. Immunol. 15, 354-364 (2014).

41. Mor, G., Cardenas, I., Abrahams, V. \& Guller, S. Inflammation and pregnancy: the role of the immune system at the implantation site. Ann. NY Acad. Sci. 1221, 80-87 (2011).

42. Saito, S., Nakashima, A., Shima, T. \& Ito, M. Th1/Th2/Th17 and regulatory T-cell paradigm in pregnancy. Am. J. Reprod. Immunol. 63, 601-610 (2010).

43. Mortha, A. et al. Microbiota-dependent crosstalk between macrophages and ILC3 promotes intestinal homeostasis. Science 343, 1249288 (2014).

44. Villanova, F. et al. Characterization of innate lymphoid cells in human skin and blood demonstrates increase of NKp44 + ILC3 in psoriasis. J. Invest. Dermatol. 134, 984-991 (2014).

45. Kitaya, K., Yasuda, J., Yagi, I., Tada, Y., Fushiki, S. \& Honjo, H. IL-15 expression at human endometrium and decidua. Biol. Reprod. 63, 683-687 (2000).
46. Montaldo, E., Juelke, K. \& Romagnani, C. Group 3 innate lymphoid cells (ILC3s): Origin, differentiation, and plasticity in humans and mice. Eur. J. Immunol. 45, 2171-2182 (2015).

47. Colucci, F. \& Kieckbusch, J. Maternal uterine natural killer cells nurture fetal growth: in medio stat virtus. Trends Mol. Med. 21, 60-67 (2015).

48. Vacca, P. et al. CD34+ hematopoietic precursors are present in human decidua and differentiate into natural killer cells upon interaction with stromal cells. Proc. Natl. Acad. Sci. USA 108, 24022407 (2011).

49. Rigo, A. et al. Macrophages may promote cancer growth via a GM-CSF/ HB-EGF paracrine loop that is enhanced by CXCL12. Mol. Cancer 9, 273 (2010).

50. Tamassia, N., Cassatella, M.A. \& Bazzoni, F. Fast and accurate quantitative analysis of cytokine gene expression in human neutrophils by reverse transcription real-time PCR. Methods Mol. Biol. 412, 455-471 (2007). 